\title{
Green Marketing and Sustainable Development: the Expanding Promotion of Organic Products into the West African Market
}

\author{
Papa Semou Faye ${ }^{1, a,{ }^{*}}$ and NGOMAH LE TEMPS Décide Amour Prestige ${ }^{2, b}$ \\ ${ }^{1}$ Wuhan University of Technology (WHUT) Wuhan, CHINA \\ ${ }^{2}$ International Students Dormitory (Nanhu) Wuhan address of second author, CHINA \\ afpapesemou@yahoo.fr, ${ }^{b}$ letempsdecide@gmail.com \\ ${ }^{*}$ Corresponding author
}

Keywords: Organic product, green marketing, West Africa.

\begin{abstract}
The organic product sector is currently experiencing an important boom and is becoming an indispensable component of the agri-food landscape. The new "Health" and "safety" trends in food consumption as well as increased interest for the environment greatly stimulate this industry in the world. With the advent of a new market for these products, areas devoted to organic farming have rapidly progressed, while processing companies and distribution channels have organized themselves to develop an offer varied and adapted to the tastes of the consumers. However, despite this dynamism and the growth of consumption, the sector shows some signs of weakness while struggling with constraints that may penalize its strategic development in the medium and long term.
\end{abstract}

\section{Theoretical Framework for Understanding Organic Product Marketing}

\section{The Organic Products in the World}

With consumers at the rendezvous, organic farming has reached a rate of historical growth. To publicize its values, principles and diversity of products, Bio has provided a powerful information and awareness program for all audiences. It is thus found on television, on radio but also on the web, on social networks and on mobile.

Organic farming in the world has been growing for five years. Although difficult to update, the available figures are increasingly reliable. At the end of 2004, organic production was estimated to account for nearly 32 million hectares with 622782 farms spread over 120 countries. Through the following illustrations, we can see that the global area in bio has quadrupled in six years and that the configurations of it are very different depending on the country. Finally, according to the experts, the evolution seems to be maintained because of the involvement of some countries like China...

Although European surfaces represent only $21 \%$ of the total organic area, Europe remains the most committed continent. Indeed, the indicator that makes it possible to assess a country's commitment to bio is its share of the surface devoted to organic farming. The countries with the largest areas, such as Australia, China and Argentina, devote only 2.71\%, $0.60 \%$ and $1.58 \%$.

\section{Evolution of Sales and Market Shares in This Sector}

Around the world, many citizens and economic agents such as agricultural producers, consumers, processors and other entrepreneurs, as well as government, continue to turn to agriculture and food in response to the uncertainty created by different environmental and social situations. The evolution of the market for organic products, which has been growing over the last 10 years, should therefore continue.

In 2009, the global organic food market amounted to nearly US $\$ 55$ billion. Between 2000 and 2009, sales of organic products worldwide have more than tripled. However, the growth recorded in 2009 was lower than in previous years, less than 10\%, due to the turmoil in the global economy. Although the data are not yet available, it is estimated that this growth would have resumed at a rate of more than $10 \%$ in 2010 (Willer and Kilcher, 2011).

The American market represents just under half of the world market. Its annual growth rate was $15 \%$ to $20 \%$ per year between 2002 and 2008 (OTA, 2011). Indeed, while the market represented US $\$ 10.4$ 
billion in 2003, it reached 26.7 billion million in 2010 (OTA 2011). As with the world market for organic products, however, its growth rate declined in 2009 because of the economic crisis.

The penetration rate of organic products in the U.S. food market has been steadily increasing over the last decade and reached $4 \%$ in 2010. In contrast to the conventional agri-food market, growth in the organic market seemed to restart in 2010 compared to 2009 (OTA, 2011).

\section{West African Consumers and Organic Products}

A majority associates the Bio with natural and healthy food products, of excellent quality and without risk to health, and which are a means of protecting the planet. When asked what brought them to the Bio, one-third of the respondents indicated an awareness of media pressure, and a quarter mentioned an individual cause, such as the arrival of a child. $95 \%$ believe that the bio will continue to grow, but only $19 \%$ believe that eventually all products will be organic.

Among the reproaches made to the Bio, it is their price too high that comes in the lead, followed by their lack of accessibility, and by the too important fashion effect that the manufacturers benefit. The lack of efficiency is also mentioned regarding organic cosmetics, while for food consumers regret the least good conservation of products and their strange taste and texture (especially for products Processed).

It is interesting to note that organic is mainly associated with products, not brands or labels. Only the $\mathrm{AB}$ label is quite well recognized, but all the others seem very blurry for consumers. Some even question the existence of these labels, because they feel that they are not accessible to small producers.

Consumers are generally waiting for better accessibility and more reasonable prices to buy more organic products, but they still entrust to be very attached to certain large non-organic brands, especially because of the qualities Sensory (taste, texture, fragrance) Superior of their products.

There is also a significant discrepancy between consumer statements about their environmental concerns and the actual purchases they make in stores, particularly on food. On the other hand, it indicates that for organic products, a substantial proportion of purchases is decided in store, hence the importance of investing in shelves (POS, animations) to better convince potential buyers.

In terms of products, fruits and vegetables are most strongly acclaimed by consumers (93\%), followed by fresh produce $(79.43 \%)$ and grocery store $(76 \%)$. If the price remains one of the brakes to the consumption of organic products, they are $25 \%$ to understand the high tariffs. On the other hand, to consume more, they think $66 \%$ that prices should be reduced, $48.2 \%$ want a more extensive offer and the same number wants more points of sale. The development of the sector still offers a strong potential because $50 \%$ of the respondents still claim to buy mostly conventional products.

\section{SHARE OF THE FREQUENCY OF ORGANIC FOOD CONSUMPTION IN 2017}

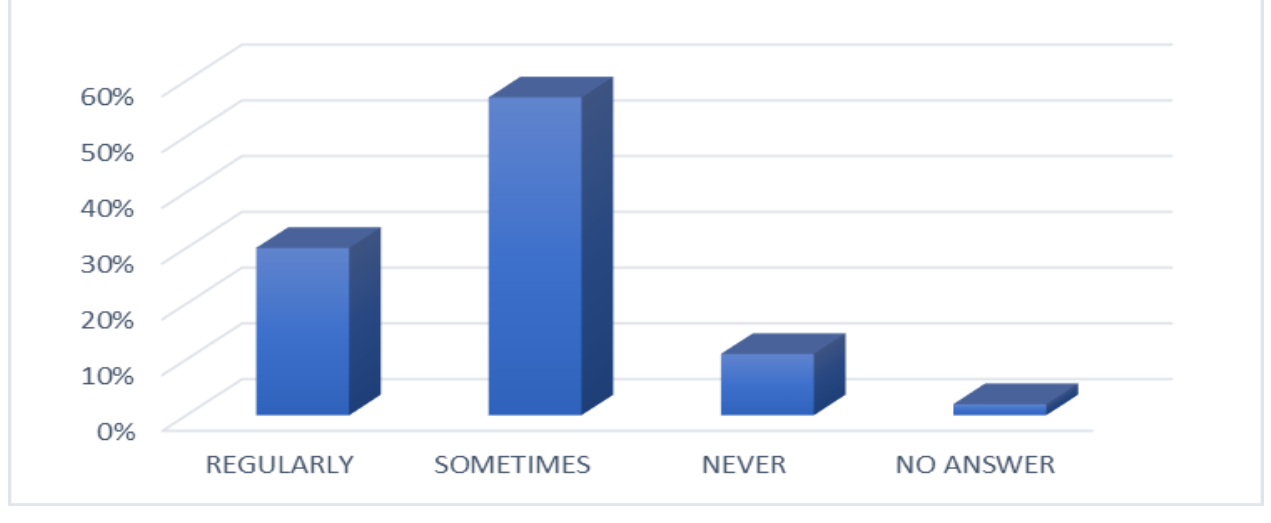

Fig. 1

This survey shows the share of consumption frequency of west African organic food products in 2016. It is found that more than $10 \%$ of respondents said never to consume. 


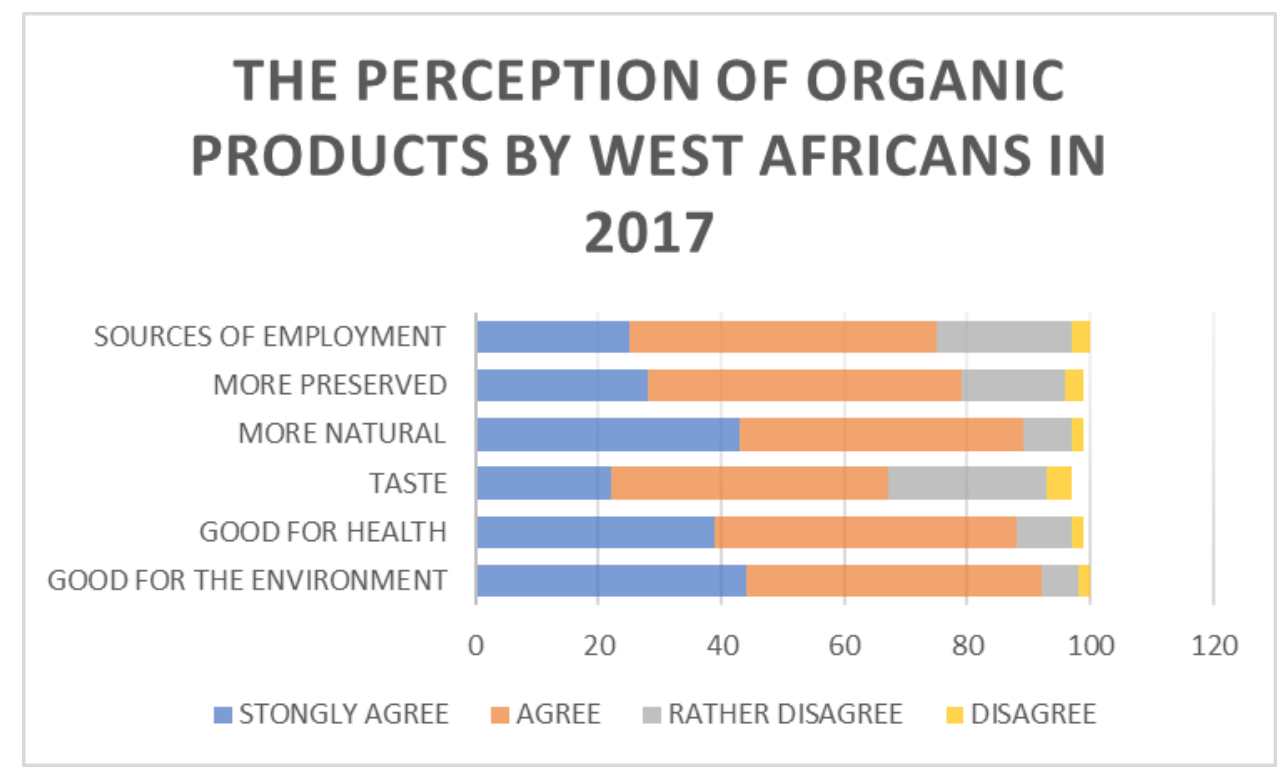

Fig. 2

This statistic represents the way the west African perceive organic products in 2016. The survey results reveal that $44 \%$ of respondents in west Africa strongly agreed that organic products are good for the environment.

\section{Unforeseen Side Effects}

The expansion of the organic market in west Africa, politically desired, reached a stage whose side effects were not initially envisaged. Yet this expansion still falls short of the original ambitions,

The ever-growing palette of BIOS products intensifies competition on domestic producers and forces them to take a more pragmatic economic orientation. While organic agriculture aims to promote local products, the expansion of the market implies the use of import.

The obligation to adapt to traditional economic structures coupled with increased economic orientation threatens not only the quality of the organic products but also the credibility of the traditional actors of the bio, this adaptation Thus threatens the steady and steady growth that has been observed in this market. Worse, many positive aspects of sustainable food (quality, traceability, etc...) remain silent.

\section{Develop Vertical Coordination Initiatives and Value Chains}

Several sectors of the organic industry remain in a low-volume production situation, which places them in a difficult position to reach certain buyers who require regular supplies. Indeed, many producers, especially in meats, would need "easy" outlets that value their organic production to justify a transition to biological. Moreover, because of the smallness of the meat and several cereals, fruits and vegetables, the entry and exit of only a few producers can significantly vary the supply, which can compromise the satisfaction of Some markets and even the situation of producers and processors.

In such situations, two approaches allow for a continuous supply and appear to be relevant: first, supply on the world market (where possible, in the case of cereals, and to a lesser extent, of meat and fruit and vegetables) until local production meets the needs and secondly, vertical coordination.

The latter option was often mentioned as a priority in those sectors that do not have a sales or supply management agency.

Vertical coordination refers to "cartels" between different links in a supply chain. In some respects, it is a concept synonymous with that of a value chain. The level of formalization of these agreements varies according to a gradient. These agreements may be verbal: they will, in fact, be very little restrictive for the parties involved. The parties may sign a supply contract: this form of risk and profit sharing offers several advantages:

- Upstream companies secure their outlets or a portion of them to pre-known volumes and prices. 
- Downstream companies secure their supplies or a portion of them to pre-known volumes and prices.

- $\quad$ Participating companies may include long-term quality improvement elements in contracts such as varietal selection, seed supply, and agronomic advice.

At the extreme of the spectrum, we find "integration": these are situations where a company owns activities upstream or downstream of its main activity. In the last decade, the need for coordination and the consolidation of supply has been identified and several successful marketing initiatives are focusing on coordination in one form or another.

The market for organic products continues to behave like a niche market. The operators who make their marketing are therefore aimed at specific segments of the population, which they must identify well to be able to join them with the good market (mix). In this respect, the considerable progress that has been made in recent years will have to continue, because in the context of stagnant and uncertain food markets, the more organic products gain market share, the more threatening they are for Agents that are already on the market. They sometimes have important development and promotion budgets. The promoters of organic products are therefore facing an increasingly organized competition and therefore need to be more and more convincing to the end consumers, not only because of their organic name, but also with the help of all the Attributes of their market (marketing mix) such as price, positioning, packaging, promotion, etc.

In practical terms, the sector could facilitate the establishment of training program which would demonstrate to certain target audiences of producers 1) The benefits of understanding the practices of buyers; 2) The benefits of developing a good marketing mix; 3) How to develop a good marketing mix that allows to reach the buyer and the final consumer.

\section{Conclusion}

Several observations can be made at the end of this analysis. First, there is the fact that the market for organic products remains marked by a chronic shortage of domestic supply; It is not able to satisfy an application that is currently in full growth.

To sum-up, the organic food processing industry has a strong demand. But the sector must overcome many more constraints if it wants to improve its return. Moreover, in the future, the growing interest of some countries in the introduction of organic foodstuffs on the market, such as China and Brazil, which can commercialize a wide variety of products at very competitive prices, will increase Competition and bring the prices of products downwards.

\section{Acknowledgement}

We would like to show our gratitude to Mr. Song Yinghua and Qin Yuanjian Wuhan University of Technology for giving us a good guideline for assignment throughout numerous consultations. We would also like to expand our deepest gratitude to all those who have directly and indirectly guided us in writing this paper.

\section{References}

[1] D.S. Zhang, G.C. Pang, Q.S. Chen the development status and prospects of organic agriculture and organic food at home and abroad Food Sci., 24 (8) (2003), pp. 188-191.

[2] Y.M. Xie, C. Ma International comparison of organic agriculture and organic food prices Theory Pract. (5) (2012), pp. 84-85.

[3] A. Tetley, J. Brunstrom, P. Griffiths Individual differences in food-cue reactivity. The role of BMI and everyday portion-size selections, Appetite, 52 (2009), pp. 614-620.

[4] J.B. Schor, M. Ford From tastes great to cool: children's food marketing and the rise of the symbolic J L Med Ethics, 35 (2007), pp. 10-21. 
[5] WALAGA, C, 2006. The development of organic agriculture sector in Africa: potential and challenges. Report on organic agriculture worldwide. http://www.rafiusa.org/pubs/ OrganicReport.pdf Accessed 13 October 2006. 